\title{
Intention toward condom use and its associated factors among students of Debre Work Senior Secondary and Preparatory School, East Gojjam Zone, Amhara Region, Ethiopia
}

This article was published in the following Dove Press journal:

HIVIAIDS - Research and Palliative Care

19 June 2017

Number of times this article has been viewed

\author{
Habtamu Abera' \\ Fanta Tamiru ${ }^{2}$ \\ Getiye Dejenu Kibret ${ }^{2}$ \\ 'Department of Nursing and \\ Midwifery, School of Allied Health \\ Sciences, Addis Ababa University \\ College of Health Sciences, Addis \\ Ababa, ${ }^{2}$ Department of Public Health, \\ College of Health Scienc, Debre \\ Markos University, Debre Markos, \\ Ethiopia
}

Objective: The main aim of this research was to investigate the students' intention toward condom use and associated factors among students in Debre Work Secondary and Preparatory School, 2015.

Methods: A survey was carried out in the high school and the preparatory school. The selfadministered semistructured questionnaire was distributed to 422 students. Systematic sampling techniques were employed to each class. Data were entered and analyzed by using SPSS version 20.0 software. Descriptive and analytical data analysis and presentation were used. Logistic regression model was used to check independent associations.

Result: Most (80.8\%) of the respondents were not married. More than half (53.0\% and 52.3\%) of the respondents had low perceived benefit and low perceived self-efficacy of using condom. About $46.79 \%$ of respondents had an interest in using condoms and the rest had no intention. Males were 1.96 times more likely to have intention to use condom compared to females (adjusted odds ratio [AOR], 95\% confidence interval [CI] 1.96 [1.29, 2.99]). When the intention to use condoms was compared, married respondents were 2.41 times more likely than those who were not married (AOR, 95\% CI 2.41 [1.41, 4.14]). Intention to use condoms among respondents who had high perceived benefit of using condom were 1.57 times more compared to those who had low perceived benefit of using condom (AOR, 95\% CI 1.57 [1.03, 2.39]). Intention to use condoms among those who had high perceived self-efficacy on condom use was 4.37 times higher compared to those who had low perceived self-efficacy (AOR, 95\% CI 4.37 [2.85, 6.71]). Conclusion: The level of intention to use condoms among students of Debre Work Senior Secondary and Preparatory School was low. Sex, current marital status, perceived benefit of using condom, and perceived self-efficacy on condom use were the most positive contributing factors for intention to condom use.

Keywords: condom, intention, high school students, health belief model condom use, HIV risk

\section{Background}

According to The United States Agency for International Development Global Report on the Global AIDS Epidemic, condom use is the basic means for protecting against HIV/AIDS and other sexually transmitted infections (STIs). Making condoms more accessible, lowering the cost of condoms, promoting awareness extensively, and helping to overcome social and personal obstacles that limit the use of condoms are some of the widely advocated strategies that can be used to prevent loss of life due to HIV/ AIDS. ${ }^{1}$ It is scientifically undisputed that the transmission of HIV during sexual intercourse can be prevented when condoms are used correctly and consistently. Condom
Correspondence: Habtamu Abera Hareri Department of Nursing and Midwifery, School of Allied Health Sciences, Addis Ababa University College of Health Sciences, PO Box 44I2, Addis Ababa, Ethiopia

Tel +251910218513

Email habtamu.abera64@gmail.com 
use is still too low, despite decades of promotion for use in the prevention of STIs. ${ }^{2}$

HIV-related behavioral change programs have been measured against the outcomes of reduction in the number of young people initiating sexual intercourse early, the number of sexual partners, and the increase in correct and consistent use of condoms among people who are sexually active. ${ }^{3,4}$

The Ethiopian Ministry of Health report on HIV/AIDS/ STIs Behavioral Surveillance Survey indicated that condom use among young people is determined by individual and social factors. Perceived self-efficacy is one of the individual factors that can influence condom use. It is a concept derived from social cognitive theory and is considered as a factor that could potentially lead to health-related behavioral change. Perceived self-efficacy is defined as the confidence in one's ability to exhibit motivation and capability to achieve a given goal. ${ }^{5}$

\section{Statement of the problem}

There are several wide-reaching studies on knowledge, attitude, and practice of preparatory students toward AIDS. Preparatory students (grades 11 and 12, age range 18-22 years) are often viewed as being at high risk for HIV because of their propensity to engage in exploratory behavior, their need for peer social approval, and their sense of nonvulnerability. ${ }^{4}$ It is known that no intervention aimed at changing behaviors to promote health can be $100 \%$ effective; however, there is no question that the prevention programs through behavioral change work and remain the best and most cost-effective approach. ${ }^{6}$

Where curable STIs exist in a population, so does the potential for HIV. Worldwide, over 300 million new cases of curable STIs occur annually, with a regional distribution similar to that of HIV. STIs increase a person's risk of acquiring HIV. Correct and consistent condom use, and other behaviors to limit exposure to infections can prevent STIs, especially HIV. While societies and their governments may view the promotion of condom use as a means to reduce rising rates of HIV prevalence, the main reason for promotion is to offer individuals one of only three possible means of $99 \%$ effective protection from sexual infection. HIV/AIDS prevention efforts that do not include condoms as an option are incomplete and ultimately ineffective. ${ }^{7,8}$

A high rate of sexual experiences and low tendency of condom use were observed in some studies among students in Ethiopia. A Gondar College of Health Sciences study revealed that out of 383 students, $56.1 \%$ were sexually active. Among the sexually active students, only $37.1 \%$ reported ever using a condom, and of them consistent use was reported by only $6.4 \%,{ }^{9}$ whereas a study among Agaro high school students showed that $25 \%$ of the students had sexual intercourse experiences. Among those who had previous sexual exposure, more than half of the respondents, $54.4 \%$, had experiences of using a condom, of which $46.9 \%$ were always using a condom. ${ }^{10}$

A survey conducted among high school students in Addis Ababa has shown that $48 \%$ of students had knowledge about HIV/AIDS prevention and only about $15 \%$ of them were informed about various types of STIs. Another study conducted to assess the prevalence of HIV among high school and college students attending clinics for STIs in Addis Ababa showed a $19 \%$ positivity. ${ }^{11}$

In Ethiopia, there is lack of compressive information on factors that influence intention to use condoms that is based on behavioral change models. The Health Belief Model is a change framework that addresses several constructs influencing health behaviors such as condom use. Thus, it is an effort to consolidate the existing knowledge, actual condom use, and future intention to use condoms, which will be comprehensively seen by one of the behavior models, namely the Health Belief Model. ${ }^{12}$

\section{Significance of the study}

One of the key methods of HIV prevention is the use of condoms during all types of sexual intercourse, despite the fact that the government has implemented different programs to educate people regarding HIV/AIDS, STIs, and unwanted pregnancies, (the possible consequences of unsafe sex), and different preventive methods. Free condoms are made available by governmental health institutions throughout the country. Therefore, this study will be used to know the students' intention toward condom use and will be used as a baseline for further research. The result can be used to strengthen existing HIV prevention programs working toward 100\% condom use among students. The data can be valuable for policy makers, managers at different levels, different stakeholders, the education sector, the community, and the family.

\section{Objective of the study}

The aim of the study was to assess the intention to use condom and associated factors among students in Debre Work Senior Secondary and Preparatory School, East Gojjam, Amhara region, 2015.

\section{Methods \\ Study design and area}

A school-based cross-sectional study design was carried out in February 2015. The study was conducted in Debre Work 
Senior Secondary and Preparatory School, Enarji Enawuga Woreda, East Gojjam zone, Amhara, Ethiopia. In this district there is one senior secondary and preparatory school with the total number of registered students in the 2014/2015 academic year of 3,674.

\section{Study population}

Students in Debre Work Senior Secondary and Preparatory School in the academic year of 2014/2015 in the regular program, and who had been selected by the sampling procedure were the study populations of this study. Students in the age group of $<15$ years were excluded.

\section{Sample methods}

A single population proportion formula was employed to calculate the sample size by considering an assumption that the proportion of students who intended to use condoms $(P)$, which was taken from a study in Agaro High school, Ethiopia, in 2001, was $49 \%{ }^{10}$ The level of significance $(\alpha)$ was taken to be 0.05 ( $Z$-value of 1.96 at $95 \%$ confidence interval); the marginal error $(d)$ was taken to be $5 \%$, and nonresponse rate was assumed to be $15 \%$. Therefore, the final total sample size, considering 15\% (58) nonresponse rate, was 442 . Systematic random sampling was used to select the study subjects considering the sampling interval $(K)$, the total source population $(\mathrm{N}=3,674)$ divided by the final total sample size $(n=442)$, that is, $N / n=3673 / 442 \approx 8$. Randomly, the fifth student was selected according to the bench arrangement from the first section (section $\mathrm{A}$ ) of grade 9 as the first sample, then every eighth student was taken to the last section of grade 12 till the final total sample size. When a student was absent from his/her bench during the time of data collection, revisit was done up to 3 consecutive days. Student participation was voluntary.

\section{Variables of the study}

The dependent variable was intention to use condoms; and the independent variables were sociodemographic, age, sex, religion, marital status, grade level, educational status of parents, currently living with family, having father alive, having mother alive, knowledge about the use of condoms and HIV/AIDS, attitude regarding condoms and HIV/AIDS, and past sexual experience.

\section{Operational definitions Students' intention to use condoms}

Regardless of their past sexual experience the students were assessed for their intention to use a condom in their next sexual encounter, using the following item: "I intend to use a condom at the next sexual intercourse." Responses were arranged from strongly agree to strongly disagree on a 5-point scale. The responses were categorized as intention to use a condom or not. The neutral response was categorized to the no intention to use scale.

\section{Students' perceived susceptibility}

Students were asked regarding perceived susceptibility to HIV/AIDS. Items such as "I am at low risk for HIV infection" and "I am too young to get an HIV infection."

\section{Students' perceived severity}

Students were asked questions regarding perceived severity of the HIV/AIDS virus. Items such as "If I had an HIV infection, my family relationships would be strained" and "If I got AIDS, I would eventually die from it."

\section{Students' perceived benefits}

An item that suggests among other things that condom use is an effective way of preventing the transmission of the AIDS virus.

\section{Students' perceived barriers}

An item that suggests that buying or using condoms is embarrassing or expensive, and indicates mistrust.

\section{Self-efficacy}

Items such as "confidence to use a condom in the middle of sexual excitement" and "high confidence in using a condom in different situations such as after alcohol use" were included.

A sum score was constructed by adding the items corresponding to each variable and dichotomized into low and high. The variable score less than or equal to the mean score was considered low, whereas that greater than the mean score was high. The response options for each item in the variables were on a 5-point Likert scale ranging from "strongly disagree to strongly agree."

\section{Data collection method, quality, and analysis}

A semistructured, self-administered questionnaire was prepared, adapting from different literatures. The questionnaire was prepared in English, translated to Amharic, and then translated back to English to check for consistency. Data were collected by four diploma-graduated nurses, and two supervisors participated during the data collection. 
Training was given to data collectors and supervisors for half a day on the content of the tool. Before going to data collection, pretest was done on 45 students in Bichena Senior Secondary and Preparatory School. After pretest, adjustments were made to a few questions on problems related to the meanings of variables, and time that needs to be taken was also adjusted. During data collection, the principal investigators and the supervisors supervised appropriately. The principal investigators monitored and evaluated the data collection procedure. The data were entered and analyzed using SPSS version 20.0 statistical package. Data cleaning was performed to check for frequencies, accuracy, consistencies, and missed values and variables. Variables with a $p$-value of $\leq 0.3$ in the bivariate analysis were considered for multivariate analysis. Logistic regression analysis was done. A $p$-value of 0.05 was considered to declare independent association. Results were displayed in text, graphs, and tables.

\section{Ethical consideration}

Ethical clearance and letter of support was obtained from the Ethical Review Committee of Medicine and Health Sciences College, Debre Markos University. Permission to conduct the study was obtained from the school administration and students' parent representatives. Informed consent was obtained from students aged $\geq 18$ years old, and for those students $<18$ years old consent was obtained from the schools representative families as well as assent from the student. Each data collector and supervisor received a copy of the permission letter from the school management. The confidentiality of the participants' response was maintained by eliminating their names from the questionnaire.

\section{Results}

\section{Sociodemographic result}

From the total 442 study participants only 421 completed the questionnaire; this makes the response rate $95.3 \%$. The age of respondents ranged from 15 to 24 years with a mean \pm SD age of $18.34 \pm 1.71$ years. More than half, $51.8 \%$, of the respondents were male. Most (80.8\%) of the respondents were not married and 19.2\% were married. Most (95.5\%) of the respondents were orthodox in religion and $4.5 \%$ were protestant. More than half, $51.8 \%$, of the respondents' mothers' educational level was at cannot read and write, whereas $49.7 \%$ of their fathers could read and write (Table 1).

\section{Knowledge, attitude, and practice of condom use}

Almost two-thirds (65.6\%) of the respondents had sufficient knowledge on condom use and HIV/AIDS, and most (91.9\%)
Table I Sociodemographic result of respondents at Debre Work Senior Secondary and Preparatory School

\begin{tabular}{|c|c|c|}
\hline Variable & $\begin{array}{l}\text { Number } \\
(\mathrm{N}=42 \mathrm{I})\end{array}$ & Percent \\
\hline \multicolumn{3}{|l|}{ Sex } \\
\hline Male & 218 & 51.8 \\
\hline Female & 203 & 48.2 \\
\hline \multicolumn{3}{|l|}{ Age (years) } \\
\hline $15-19$ & 297 & 70.5 \\
\hline $20-24$ & 124 & 29.5 \\
\hline \multicolumn{3}{|l|}{ Current marital status } \\
\hline Married & 81 & 19.2 \\
\hline Not married & 340 & 80.8 \\
\hline \multicolumn{3}{|l|}{ Religion } \\
\hline Orthodox & 402 & 95.5 \\
\hline Protestant & 19 & 4.5 \\
\hline \multicolumn{3}{|l|}{ Currently living with family } \\
\hline Yes & 308 & 73.2 \\
\hline No & 113 & 26.8 \\
\hline \multicolumn{3}{|l|}{ Have father alive } \\
\hline Yes & 366 & 86.9 \\
\hline No & 55 & 13.1 \\
\hline \multicolumn{3}{|c|}{ Educational level of father alive $(n=366)$} \\
\hline Cannot read and write & 97 & 26.5 \\
\hline Can read and write & 182 & 49.7 \\
\hline Grade I-4 & 43 & 11.7 \\
\hline Grade 5-8 & 18 & 4.9 \\
\hline Grade 9-12 & 20 & 5.5 \\
\hline Above grade 12 & 6 & 1.6 \\
\hline \multicolumn{3}{|l|}{ Have mother alive } \\
\hline Yes & 398 & 94.5 \\
\hline No & 23 & 5.5 \\
\hline \multicolumn{3}{|c|}{ Educational level of alive mother $(n=398)$} \\
\hline Cannot read and write & 206 & 51.8 \\
\hline Can read and write & 107 & 26.9 \\
\hline Grade I-4 & 44 & 11.1 \\
\hline Grade 5-8 & 13 & 3.3 \\
\hline Grade 9-12 & 24 & 6.0 \\
\hline Grade $>12$ & 4 & 1.0 \\
\hline
\end{tabular}

of the respondents had good attitude toward condom use and HIV/AIDS. One-seventh (14.3\%) of the respondents had ever had sexual intercourse. The age of first sex of these respondents ranged from 10-23 years with a mean \pm SD age of $17 \pm 3.09$ years. From those respondents who had ever had sex, more than two-thirds (38.3\%) had used a condom, and among these, almost half (52.2\%) used a condom "sometimes" during sex (Table 2).

\section{Health Belief Model constructs and intention to condom use}

Most (88.1\%) of the respondents had low perceived susceptibility to HIV. About $53.0 \%$ of the respondents had low perceived benefit of using condom. Slightly higher than half $(52.3 \%)$ of the students had low perceived self-efficacy on 
Table 2 Knowledge-, attitude-, and practice-related results of respondents at Debre Work Senior Secondary and Preparatory School

\begin{tabular}{|c|c|c|}
\hline Variable & $\begin{array}{l}\text { Number } \\
(\mathrm{N}=42 \mathrm{I})\end{array}$ & Percent \\
\hline \multicolumn{3}{|c|}{ Knowledge on condom use and HIVIAIDS } \\
\hline Sufficient knowledge & 276 & 65.6 \\
\hline Insufficient knowledge & 145 & 34.4 \\
\hline \multicolumn{3}{|c|}{ Attitude toward condom use and HIVIAIDS } \\
\hline Good attitude & 387 & 91.9 \\
\hline Poor attitude & 34 & 8.1 \\
\hline \multicolumn{3}{|l|}{ Have ever seen a condom } \\
\hline Yes & 322 & 76.5 \\
\hline No & 99 & 23.5 \\
\hline \multicolumn{3}{|c|}{ Have ever practiced sexual intercourse } \\
\hline Yes & 60 & 14.3 \\
\hline No & 361 & 85.7 \\
\hline \multicolumn{3}{|c|}{ Age at first sex (years) $(n=60)$} \\
\hline $10-14$ & 8 & 13.3 \\
\hline $15-19$ & 43 & 71.7 \\
\hline $20-24$ & 9 & 15.0 \\
\hline \multicolumn{3}{|c|}{ Number of sexual partners $(n=60)$} \\
\hline Only one & 50 & 83.3 \\
\hline Two and above & 10 & 16.7 \\
\hline \multicolumn{3}{|c|}{ Condom used during sex $(n=60)$} \\
\hline Yes & 23 & 38.3 \\
\hline No & 37 & 61.7 \\
\hline \multicolumn{3}{|c|}{ Frequency of using condom during sex $(n=23)$} \\
\hline Sometimes & 11 & 47.8 \\
\hline Regularly & 12 & 52.2 \\
\hline
\end{tabular}

condom use (Table 3 ). Less than half (46.8\%) of them had intention to use condom (Figure 1).

\section{Determinate of intention to use condom}

The multivariate logistic regression that controls the undesirable effect of confounding variables was used and the method was backward (unconditional). All the eight covariates (sex, current marital status, attitude toward condom use and HIV/ AIDS, have ever seen condom, have ever practiced sexual intercourse, perceived benefit of using condom, perceived threat of not using condom, and perceived self-efficacy on condom use) that were significant at the bivariate analyses were entered simultaneously to see the relationship with the dependent variable. Only four of the most contributing factors were statistically associated at 0.05 level of significance and were independently associated with intention to use condom. Men were 1.96 times more likely to have intention to use condom compared to females (adjusted odds ratio [AOR], 95\% 1.96 [1.29, 2.99]). The intention to use condom among married respondents was 2.41 times more compared to those who were not married (AOR, 95\% CI $2.41[1.41,4.14])$. The condom use intention among
Table 3 Result on Health Belief Model constructs of respondents at Debre Work Senior Secondary and Preparatory School

\begin{tabular}{|c|c|c|}
\hline Variable & $\begin{array}{l}\text { Frequency } \\
(\mathrm{N}=421)\end{array}$ & Percent \\
\hline \multicolumn{3}{|c|}{ Perceived susceptibility to HIV } \\
\hline High & 50 & 11.9 \\
\hline Low & 371 & 88.1 \\
\hline \multicolumn{3}{|c|}{ Perceived severity of HIV/acquired immune deficiency syndrome } \\
\hline High & 163 & 38.7 \\
\hline Low & 258 & 61.3 \\
\hline \multicolumn{3}{|c|}{ Perceived benefit of using condom } \\
\hline High & 198 & 47.0 \\
\hline Low & 223 & 53.0 \\
\hline \multicolumn{3}{|c|}{ Perceived barriers to condom use } \\
\hline High & 98 & 23.3 \\
\hline Low & 323 & 76.7 \\
\hline \multicolumn{3}{|c|}{ Perceived threat of not using condom } \\
\hline High & 105 & 24.9 \\
\hline Low & 316 & 75.1 \\
\hline \multicolumn{3}{|c|}{ Perceived self-efficacy on condom use } \\
\hline High & 201 & 47.7 \\
\hline Low & 220 & 52.3 \\
\hline
\end{tabular}

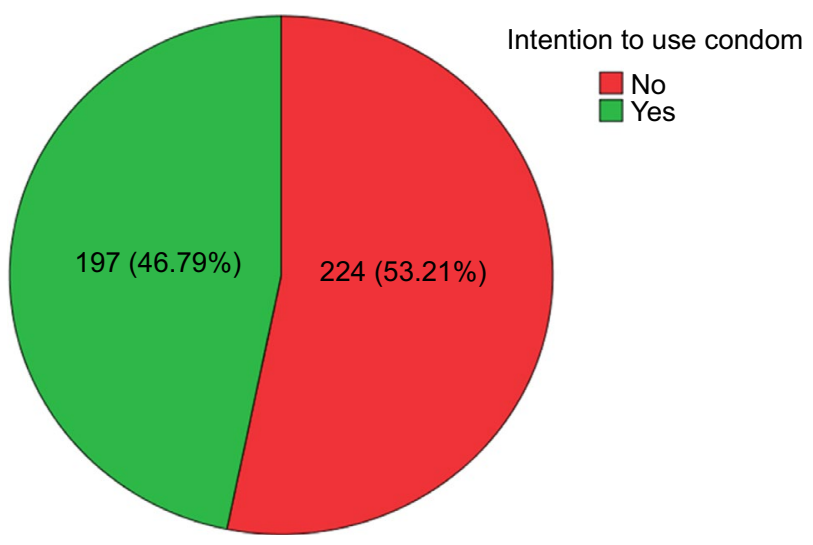

Figure I The level of intention to use condom of respondents at Debre Work Senior Secondary and Preparatory School.

those with high perceived benefit of using condom was 1.57 times more compared to those who had low perceived benefit of using condom (AOR, 95\% CI 1.57 [1.03, 2.39]). Respondents who had high perceived self-efficacy on condom use were 4.37 times more compared to those who had low perceived self-efficacy (AOR, 95\% CI 4.37 [2.85, 6.71]) (Table 4).

\section{Discussion}

Almost two-thirds (65.6\%) of the respondents had sufficient knowledge on condom use and HIV/AIDS. Additionally, $91.9 \%$ of the respondents had good attitude toward condom use and HIV/AIDS. However, a result found by Abraha and Berhanu ${ }^{13}$ among secondary school students in Mekelle City (Ethiopia) showed that both knowledgeable students and 
Table 4 Result of multivariate analyses (factors associated with intention to condom use) among respondents at Debre Work Senior Secondary and Preparatory School

\begin{tabular}{|c|c|c|c|c|c|}
\hline \multirow[t]{2}{*}{ Independent variable } & \multicolumn{2}{|c|}{ Intention to use condom $(\mathrm{N}=\mathbf{4 2} \mathrm{I})$} & \multirow{2}{*}{$\begin{array}{l}\text { Corrected odds } \\
\text { ratio }(95 \% \mathrm{CI})\end{array}$} & \multirow{2}{*}{$\begin{array}{l}\text { Adjusted odds } \\
\text { ratio }(95 \% \mathrm{Cl})\end{array}$} & \multirow[t]{2}{*}{$p$-value } \\
\hline & Yes, n (\%) & No, n (\%) & & & \\
\hline \multicolumn{6}{|l|}{ Sex } \\
\hline Male & $|2|(55.5)$ & $97(44.5)$ & $2.09(1.41,3.08)$ & $1.96(1.29,2.99)$ & 0.002 \\
\hline Female & $76(37.4)$ & $127(62.6)$ & 1.00 & 1.00 & \\
\hline \multicolumn{6}{|l|}{ Current marital status } \\
\hline Married & $48(59.3)$ & $33(40.7)$ & $1.87(1.14,3.05)$ & $2.41(1.41,4.14)$ & 0.001 \\
\hline Not married & $149(43.8)$ & $191(56.2)$ & 1.00 & 1.00 & \\
\hline \multicolumn{6}{|c|}{ Perceived benefit of using condom } \\
\hline High & $108(54.5)$ & $90(45.5)$ & $1.81(1.23,2.66)$ & $1.57(1.03,2.39)$ & 0.036 \\
\hline Low & $89(39.9)$ & $134(60.1)$ & 1.00 & 1.00 & \\
\hline \multicolumn{6}{|c|}{ Perceived self-efficacy on condom use } \\
\hline High & $130(64.7)$ & $71(35.3)$ & $4.18(2.78,6.29)$ & $4.37(2.85,6.7 I)$ & $<0.001$ \\
\hline Low & $67(30.5)$ & $153(69.5)$ & 1.00 & 1.00 & \\
\hline \multicolumn{6}{|c|}{ Attitude toward condom use } \\
\hline Good & $185(47.8)$ & $202(52.2)$ & $1.68(0.81,3.49)$ & $1.63(0.73,3.62)$ & 0.24 \\
\hline Poor & $12(35.3)$ & $22(64.7)$ & 1.00 & 1.00 & \\
\hline \multicolumn{6}{|l|}{ Have ever seen a condom } \\
\hline Yes & $162(50.3)$ & $160(49.7)$ & $1.85(1.16,2.95)$ & $1.35(0.77,2.36)$ & 0.29 \\
\hline No & $35(35.4)$ & $64(64.6)$ & 1.00 & 1.00 & \\
\hline \multicolumn{6}{|c|}{ Perceived threat of not using condom } \\
\hline High & $56(53.3)$ & $49(46.7)$ & $\mathrm{I} .42(0.9 \mathrm{I}, 2.2 \mathrm{I})$ & $1.23(0.76,2.01)$ & 0.39 \\
\hline Low & $14 \mid(44.6)$ & $175(55.4)$ & 1.00 & 1.00 & \\
\hline \multicolumn{6}{|c|}{ Have ever had sexual intercourse } \\
\hline Yes & $33(55)$ & $27(45)$ & $1.47(0.85,2.54)$ & $1.03(0.55,1.93)$ & 0.93 \\
\hline No & $164(45.4)$ & $197(54.6)$ & 1.00 & 1.00 & \\
\hline
\end{tabular}

those having good attitude on condom use was at $70 \%$. Even if the difference is not high, this little difference might be due to measurement difference (this study used Likert scale to measure knowledge and attitude).

In this study, about $14.3 \%$ of the respondents had ever practiced sexual intercourse. However, three studies that had been conducted by Belaineh et $\mathrm{al}^{10}$ at Agaro High School, Gebreselassie et $\mathrm{al}^{14}$ at Agena Preparatory School, and Abraha $\mathrm{T}^{13}$ et al at Mekelle Secondary School showed that the proportion of students who had practiced sexual intercourse was $25 \%, 27.1 \%$, and $26.3 \%$, respectively. This difference might be due to the difference in cultural norm, because the study areas are in different regions of the country.

The finding of this study showed about $38.3 \%$ of the respondents who had ever had sex used a condom. This finding is in line with the finding by Yohannis et $\mathrm{al}^{9}$ at Gondar $(37.1 \%)$, but lower than the three studies conducted by Belaineh et $\mathrm{al}^{10}$ at Agaro High School, Gebreselassie et $\mathrm{al}^{14}$ at Agena Preparatory School, and Abraha et al ${ }^{13}$ at Mekelle secondary school with condom use result of $54.4 \%, 63.1 \%$, and $75 \%$, respectively. This difference could be related to study knowledge difference and lack of access.

Less than half $(46.79 \%)$ of the respondents had intention to use condom. This finding is almost in line with the finding by Belaineh et $\mathrm{al}^{10}$ at Agaro High School (49\%). However, it is high relative to the finding by Gebreselassie et $\mathrm{al}^{14}$ at Agena Preparatory School (33.3\%). The difference might be due to the difference of the measurement (this study used Likert scale) and may also be due to cultural differences.

The finding of this study shows that men have intention to condom use. However, sex was not an independent factor for intention to condom use in other literatures..$^{9,10,14}$ The finding in this research might be due to cultural influences; men might have also high exposure for condom use to develop confidence compared to their counterparts.

Marriage was not an independent factor for intention to use condom in other literature. ${ }^{9,10,14}$ However, married respondents in this study have intention to use condom. The finding in this research might be due to married respondents possibly having high exposure to sexual intercourse and wanting to use condom as an option for family planning.

Similarly, perceived benefit of using condom was not statistically significant in other literature. ${ }^{9,10,14}$ But the finding of this study showed that respondents with high perceived benefits of condom use have intention to use condom. This might be due to that those who perceive highly on the benefit of condom use to prevent HIV/AIDS possibly having more awareness about it. 
Respondents had high perceived self-efficacy on condom use, which is in line with Gebreselassie et al ${ }^{14}$ at Agena Preparatory School.

\section{Conclusion}

The level of intention to condom use among students of the senior secondary and preparatory school was low $(46.79 \%)$. Sex, current marital status, perceived benefit of using condom, and perceived self-efficacy on condom use were the most positive contributing factors for intention to condom use.

\section{Recommendation}

\section{To the senior secondary and preparatory school management and staff}

The senior secondary and preparatory school management and staff should design strategies to increase the students' intention to use condoms. Specifically, much effort should be made on students who are not married as well as on female students of senior secondary and preparatory school.

\section{To health office and health centers}

The district health office and health centers should design strategies and do more on perceived benefits of using condom and perceived self-efficacy on condom use for senior secondary and preparatory school students.

\section{To concerned non-government organizations on condom use}

Concerned NGOs on condom use like DKT Ethiopia should play an active role integrated with the senior secondary and preparatory school management and staff, the district health office, and health centers on intention to use condom.

\section{Acknowledgments}

We would like to thank Debre Markos University Health Sciences College for the ethical clearance and the permission given to conduct this study. We also thank the Debre Work Senior Secondary and Preparatory School teachers and management body for their intensive support during the study and finally the respondents for their genuine information.

\section{Author contributions}

All authors contributed toward data analysis, drafting and critically revising the paper and agree to be accountable for all aspects of the work.

\section{Disclosure}

The authors report no conflicts of interest in this work.

\section{References}

1. USAIDS. Global Report on the Global AIDS Epidemic. Washington, DC: USAIDS; 2012:8-17.

2. USAIDS. AIDS and other STI. Geneva, Switzerland: WHO; 2003.

3. Mohamed F. Factors Related to Voluntary HIV Counseling and Testing Among 15-49 Years Urban Community of Eastern Ethiopia. Addis Ababa: AAU; 2000:1-79.

4. Bandura A. Social Foundations of Thought and Action. Englewood Cliffs, NJ: Prentice Hall; 1986.

5. Ministry of Health. HIV/AIDS/STIs Behavioral Surveillance Survey, Round Two (BSS). Addis Ababa, Ethiopia: Ministry of Health; 2004.

6. Taffa N. Sexuality of school youth and their knowledge about STDs and HIV /ADS in southern Ethiopia. J Health Dev.1998;12(1):17-22.

7. ICN. Impacts of HIV/AIDS on Health Personnel. Geneva, Switzerland: WHO; 2003.

8. Gerald J, Stine P. AIDS Update. Englewoods Cliffs, NJ: Prentice Hall; 2003:264-307.

9. Yohannis F, Alemayehu W. High-risk sexual behavior and pattern of condom utilization of the Gondar Collage of Medical Sciences (GCMS) Students, North-west Ethiopia. Ethiop J Health Dev. 2002;16(3):335-338.

10. Belaineh G, Demeke A, Kora T. Determinants of condom use among Agaro High School students using behavioral models. Ethiop J Health Dev. 2004:18(1):25-30.

11. Gebre S. Sexual behavior and knowledge of AIDS and other STDs; a survey of senior high school students. Ethiop J Health Dev. 1990;4(2):123-131.

12. Glanz K, Rimer BK, Lewis FM. Health Behavior and Health Education. Theory, Research and Practice. San Fransisco: Wiley \& Sons; 2002.

13. Abraha T, Berhanu M. Knowledge, attitude and practice regarding HIV/ AIDS among secondary school students in Mekelle City, Ethiopia. Afr J AIDS HIV Res. 2013;1(1):1-7.

14. Gebreselassie G, Deyessa N, Tesfaye G. Intention to use condom among students in Agena preparatory school, Guraghe Zone, Ethiopia: with the application of health believe model. Arch Public Health. 2013;71(1):23.
HIV/AIDS - Research and Palliative Care

\section{Publish your work in this journal}

HIV/AIDS - Research and Palliative Care is an international, peerreviewed open access journal focusing on advances in research in HIV its clinical progression and management options including antiviral treatment, palliative care and public healthcare policies to control viral spread. The journal is included in PubMed. The manuscript man-

\section{Dovepress}

agement system is completely online and includes a very quick and fair peer-review system, which is all easy to use. Visit http://www.dovepress. com/testimonials.php to read real quotes from published authors. 